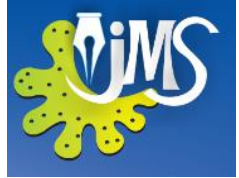

\title{
Investigation of Optimum pH and Temperature for In-Vitro Crystallization of Urinary Cystine
}

\author{
Gunawardana A.D.U.R. ${ }^{1}$, Amarasingha K.N.L. ${ }^{1}$ and Priyadarshani A.M.B. ${ }^{{ }^{*}}$ \\ ${ }^{1}$ Department of Medical Laboratory Sciences, Faculty of Allied Health Sciences, University of Sri \\ Jayewardenepura, Sri Lanka
}

\begin{abstract}
Cystinuria contributes in formation of urinary stones. But, it has been reported that cystinuria is diagnosed when someone experiences with cystine stones. Therefore, early diagnosis of this condition is important. Thus, the objective of the study was to determine the optimum $\mathrm{pH}$ and temperature for crystallization of urine cystine in-vitro. Cystinuria solutions were prepared with the concentrations of 40, 60, 70, 75, 80, 90, 100 and $120 \mathrm{mg} / \mathrm{dL}$. The $\mathrm{pH}$ of each solution was changed with the addition of acetic acid. Then solutions were exposed to temperature $+4^{\circ} \mathrm{C}$ and $37^{\circ} \mathrm{C}$, for 15,30 and $45 \mathrm{~min}$. The sediments were observed microscopically for cystine crystals formation. Then acetone was added to cystinuria with the ratio of cystinuria:acetone, 8:1, 4:1, 2:1 and 1.1 and $p H$ was altered with acetic acid and were subjected to $+4{ }^{\circ} \mathrm{C}$ and $37{ }^{\circ} \mathrm{C}$, for 15,30 and 45 minutes and sediment was observed for cystine crystals under the microscope. Cystine crystallization had been occurred in the cystinuria of $\geq 100 \mathrm{mg} / \mathrm{dL}$ at $\mathrm{pH} 5$ at $37^{\circ} \mathrm{C}$ and $+4{ }^{\circ} \mathrm{C}$, 30min after the addition of acetic acid whereas with the addition of acetone at cystinuria of $\geq 75 \mathrm{mg} / \mathrm{dL}$ at $\mathrm{pH} 5$ in both $37^{\circ} \mathrm{C}$ and at $+4^{\circ} \mathrm{C}$, 30min after the addition of acetic acid. The number of cystine crystals per High Power Field (HPF) was highest where cystinuria:acetone was 8:1. The optimum conditions for cystine crystallization is at $\mathrm{pH} 5,37^{\circ} \mathrm{C}$ and +4 ${ }^{\circ} \mathrm{C}$, 30min after acidifying with acetic acid at the minimum concentration of $100 \mathrm{mg} / \mathrm{dL}$ of cystinuria. With the addition of acetone, at the ratio of cystinuria:acetone 8:1 with minimum concentration of cystinuria of $75 \mathrm{mg} / \mathrm{dL}$.
\end{abstract}

KEYWORDS: Cystine, Crystallization, Acetic acid, Acetone, Temperature, $p H$ 



\section{INTRODUCTION}

Cystinuria is an autosomal-recessive inherited disorder in reabsorption and transport of cystine and the dibasic amino acids, ornithine, arginine and lysine from the luminal membrane of the renal proximal convoluted tubule and the small intestine, which eventually characterized by hyper-excretion of cystine and dibasic amino acids into urine. Eventually cystinuria plays a vital role in formation of urinary stones, being responsible for $1-2 \%$ urinary stones in the adult whereas up to $10 \%$ in children. Though, urolithiasis caused by cystine is the only phenotypic manifestation of cystinuria, it often persists throughout the life-time of the affected individual. It is a lifelong condition and if not managed and treated properly, cystinuria can be tremendously painful and may direct to serious medical complications such as damage to the kidney or bladder, urinary tract infections, pyelonephritis, ureteral and ureter obstructions.

Several investigations have been carried out on mineralogical compositions of urinary stones revealed that cystine as one of the contributor in urinary stone formation [Keshavarzi, 2016; Takasaki, 1995; Sakandé, 2012; Biyani \& Cartledge, 2006]. Approximately $1 \%$ of adult and $6 \%$ of paediatric stones is cystine. It has been reported that estimated prevalence of cystinuria globally is 1 per 7000 individuals [Biyani \& Cartledge, 2006]. It has identified that two genes are responsible for cystinuria condition. The cystinuria type I is caused by the mutations in the SLC3A1 gene, located on the chromosome 2p, whereas non-type I cystinuria is due to variants in SLC7A9
[Jessen \& Knoll; 2012, Biyani\&Cartledge, 2006].

In addition to that the factors such as urine osmolality, dehydration, some food intake are also contributed in this condition. The reduced solubility of cystine in urine could be directed to stone formation in affected individuals. This would be manifested in the second and third decades of life. The management strategies are done to decline the urinary cystine concentration below $300 \mathrm{mg} / \mathrm{L}$ which involves plentiful oral fluid intake, urinary alkalisation and thiol medications [Biyani\&Cartledge, 2006].

The risk has been reported on recurrent formation of stones from cystine in the kidney, ureter and bladder. However, intermittent stone formation requires repetitive urological interventions with possibly impairment of renal functions and thereby quality of the life. The formation of cystine stone is initiated from neonatal stage and children are more vulnerable group to have cystine stones [Tasian \& Copelovitch, 2014].

It has been reported that cystinuria is usually diagnosed when someone experiences with an incident of cystine stones. The diagnosis is usually made by testing the stones to demonstrate that they are made out of cystine. Despite the fact that early diagnosis of cystinuria is extremely important, due to increased solubility of cystine in urine of cystine stone formers compared to normal individuals [Nakagawa, 2000] cystine crystals may absent in urine deposit even in stone formers owing to miss-diagnosis of cystinuria.

Therefore, it has become very important to identify cystinuria condition by improving and modifying microscopic screening of 
cystine crystal as a diagnostic test in urine sediment even under lower urine cystine concentrations to facilitate the early diagnosis before making complications. Hence, the objective of the present study was to determine the optimum $\mathrm{pH}$ and temperature for crystallization of urinary cystine in-vitro.

\section{MATERIALS AND METHODS}

\section{Preparation of cystine standard solution}

Concentration series of cystine standard solution was prepared starting from the minimum cystine concentration which gives a positive result for cyanide nitroprusside test. The cystine standard solution of $75 \mathrm{mg} / \mathrm{dL}$ was prepared by dissolving $75 \mathrm{mg}$ of cystine in $100 \mathrm{~mL}$ of $100 \mathrm{mmol} / \mathrm{L} \quad \mathrm{Na}_{2} \mathrm{CO}_{3}$ solution. Then different concentrations of cystine standards were prepared as given in Table 1. $\mathrm{NaCO}_{3}$ solution with100 mmol/L was prepared by dissolving $1.06 \mathrm{~g}$ of $\mathrm{NaCO}_{3}$ in $100 \mathrm{~mL}$ distilled water.

\section{Preparation of cystinuria solution}

Cystine standard solution was mixed with calculated volume of freshly voided urine sample which was collected from a 6 years old female healthy subject. According to the physical, biochemical and microscopic examination the urine sample was identified as a normal urine sample. The $\mathrm{pH}$ value of urine sample was measured by $\mathrm{pH}$ meter prior to add cystine standard solution. Concentration gradient of cystinuria solutions was $40,60,70,75,80$, 90, 100 and $120 \mathrm{mg} / \mathrm{dL}$. Preparation of cystinuria solutions was done according to the Table 1.

Table 1: Preparation of concentration gradient of cystinuria solution

\begin{tabular}{lllll}
\hline $\begin{array}{l}\text { Concentration of cystine } \\
\text { standard solution }\end{array}$ & $\begin{array}{l}\text { Volume of } \\
\text { cystine } \\
\text { standard } \\
\text { solution }\end{array}$ & $\begin{array}{l}\text { Volume of freshly } \\
\text { voided urine }\end{array}$ & $\begin{array}{l}\text { Final volume } \\
\text { of cystinuria }\end{array}$ & $\begin{array}{l}\text { Concentration } \\
\text { of cystinuria }\end{array}$ \\
\hline $\begin{array}{l}(40 \times 5)=200 \mathrm{mg} / \mathrm{dL} \\
20 \mathrm{~mL}\end{array}$ & $80 \mathrm{~mL}$ & $100 \mathrm{~mL}$ & $40 \mathrm{mg} / \mathrm{dL}$ \\
$(60 \times 5)=300 \mathrm{mg} / \mathrm{dL}$ & $20 \mathrm{~mL}$ & $80 \mathrm{~mL}$ & $100 \mathrm{~mL}$ & $60 \mathrm{mg} / \mathrm{dL}$ \\
$(70 \times 5)=350 \mathrm{mg} / \mathrm{dL}$ & $20 \mathrm{~mL}$ & $80 \mathrm{~mL}$ & $100 \mathrm{~mL}$ & $70 \mathrm{mg} / \mathrm{dL}$ \\
$(75 \times 5)=375 \mathrm{mg} / \mathrm{dL}$ & $20 \mathrm{~mL}$ & $80 \mathrm{~mL}$ & $100 \mathrm{~mL}$ & $75 \mathrm{mg} / \mathrm{dL}$ \\
$(80 \times 5)=400 \mathrm{mg} / \mathrm{dL}$ & $20 \mathrm{~mL}$ & $80 \mathrm{~mL}$ & $100 \mathrm{~mL}$ & $80 \mathrm{mg} / \mathrm{dL}$ \\
$(90 \times 5)=450 \mathrm{mg} / \mathrm{dL}$ & $20 \mathrm{~mL}$ & $80 \mathrm{~mL}$ & $100 \mathrm{~mL}$ & $90 \mathrm{mg} / \mathrm{dL}$ \\
$(100 \times 5)=500 \mathrm{mg} / \mathrm{dL}$ & $20 \mathrm{~mL}$ & $80 \mathrm{~mL}$ & $100 \mathrm{~mL}$ & $100 \mathrm{mg} / \mathrm{dL}$ \\
\hline$(120 \times 5)=600 \mathrm{mg} / \mathrm{dL}$ & $20 \mathrm{~mL}$ & $80 \mathrm{~mL}$ & $100 \mathrm{~mL}$ & $120 \mathrm{mg} / \mathrm{dL}$ \\
\hline
\end{tabular}


For the preparation of $100 \mathrm{~mL}$ cystinuria solution with $75 \mathrm{mg} / \mathrm{dL}$ concentration, 80 $\mathrm{mL}$ of freshly voided urine was mixed with $20 \mathrm{~mL}$ of cystine standard solution with $375 \mathrm{mg} / \mathrm{dL}$ concentration. Because there was a 1:5 dilution when mixed $80 \mathrm{~mL}$ urine with $20 \mathrm{~mL}$ cystine standard solution and concentration of cystine standard solution fall off with 5 times from its initial value. Therefore, to prepare cystinuria with $75 \mathrm{mg} / \mathrm{dL}$ concentration, the initial concentration of cystine standard solution was adjusted to $375 \mathrm{mg} / \mathrm{dL}$ (75mgx5).

After preparing cystinuria concentration series, $\mathrm{pH}$ value of each was measured by a calibrated $\mathrm{pH}$ meter. Then, aliquot from each cystinuria solution was centrifuged at $2000 \mathrm{rpm}$ for 5 minutes and the sediment was observed microscopically for formation of cystine crystals.

Table 2: $\mathrm{pH}$ and temperature changes done on cystinuria solution

Temperature $\quad$ pH value

\begin{tabular}{lllllll}
\hline $37^{\circ} \mathrm{C}$ & Just after the acidification & 6 & 5.5 & 5 & 4 & 3 \\
& After $15 \mathrm{~min}$ & 6 & 5.5 & 5 & 4 & 3 \\
& After 30 min & 6 & 5.5 & 5 & 4 & 3 \\
& After $45 \mathrm{~min}$ & 6 & 5.5 & 5 & 4 & 3 \\
\hline$+4^{\circ} \mathrm{C}$ & Just after the acidification & 6 & 5.5 & 5 & 4 & 3 \\
& After 15 min & 6 & 5.5 & 5 & 4 & 3 \\
& After 30 min & 6 & 5.5 & 5 & 4 & 3 \\
& After 45 min & 6 & 5.5 & 5 & 4 & 3 \\
\hline
\end{tabular}

Determination of effect of temperature on crystallization of cystine in-vitro

The temperature was altered by keeping the cystinuria solutions in refrigerator $(+4$ ${ }^{\circ} \mathrm{C}$ ) and at ambient temperature $\left(37{ }^{\circ} \mathrm{C}\right)$, for different time periods; ie., 15 minutes, 30 minutes and 45 minutes. After that, cystinuria solution from each concentration was treated with acetic acid.

\section{Determination of effect of $\mathrm{pH}$ on crystallization of cystine in-vitro}

The $\mathrm{pH}$ of prepared cystinuria solutions were adjusted to $6,5.5,5,4$ and 3 by acidifying the sample with acetic acid. All the $\mathrm{pH}$ measurements were taken by a calibrated $\mathrm{pH}$ meter.
Table 2 explains that how each cystinuria solution was treated with different $\mathrm{pH}$ values and temperatures. Before and after treating with each condition mentioned above, cystinuria solutions were observed macroscopically for the formation of precipitate. Then the samples were centrifuged at $2000 \mathrm{rpm}$ for 5 minutes and the sediment was observed microscopically for formation of cystine crystals. The $\mathrm{pH}$ and the temperature which initiate the formation of cystine hexagonal plates were taken as the optimum conditions for cystine crystallization. 
Determination of effect of acetone on crystallization of cystine in-vitro

Acetone was added to each cystinuria solution according to the Table 3 . Then $\mathrm{pH}$ and temperature were altered according to the Table 2 and urine sediment obtained from each concentration was observed under the microscope for the cystine crystal formation.

Table 3: Addition of acetone into the cystinuria solutions

\begin{tabular}{ll}
\hline $\begin{array}{l}\text { Volume of cystinuria } \\
\text { solution }\end{array}$ & $\begin{array}{l}\text { Volume of } \\
\text { acetone }\end{array}$ \\
\hline $5 \mathrm{~mL}$ & $5.00 \mathrm{~mL}$ \\
$5 \mathrm{~mL}$ & $2.50 \mathrm{~mL}$ \\
$5 \mathrm{~mL}$ & $1.25 \mathrm{~mL}$ \\
$5 \mathrm{~mL}$ & $0.625 \mathrm{~mL}$
\end{tabular}

All the tests were done in duplicate.

\section{RESULTS}

The initial $\mathrm{pH}$ of the freshly voided urine sample which used for the preparation of cystinuria solution was slightly acidic ( $\mathrm{pH}=5.65)$. After preparing cystinuria concentration series, initial $\mathrm{pH}$ of fresh urine shifted in to alkaline $\mathrm{pH}$ as indicated in Table 4.

Table 4: Initial $\mathrm{pH}$ values of cystinuria solutions

Concentration of
cystinuria solutions

\begin{tabular}{ll}
\hline $40 \mathrm{mg} / \mathrm{dL}$ & 7.52 \\
$60 \mathrm{mg} / \mathrm{dL}$ & 7.54 \\
$70 \mathrm{mg} / \mathrm{dL}$ & 7.63 \\
$75 \mathrm{mg} / \mathrm{dL}$ & 8.5 \\
$80 \mathrm{mg} / \mathrm{dL}$ & 8.07 \\
$90 \mathrm{mg} / \mathrm{dL}$ & 8.03 \\
$100 \mathrm{mg} / \mathrm{dL}$ & 7.51 \\
$120 \mathrm{mg} / \mathrm{dL}$ & 7.40 \\
\hline
\end{tabular}

Effect of pH and temperature on crystallization of cystine in-vitro

According to the microscopic observation, cystine crystals were present in the concentrations of $\geq 100 \mathrm{mg} / \mathrm{dL}$ of cystinuria solutions. Cystine crystallization had been occurred at $\mathrm{pH} 5$ in both, $37{ }^{\circ} \mathrm{C}$ and at $+4{ }^{\circ} \mathrm{C}, 30$ minutes after the addition of acetic acid (see Table 5).

Table 5: Optimum $\mathrm{pH}$ and temperature for crystallization of urinary cystine in-vitro

\begin{tabular}{llccccc}
\hline Temperature & pH values & 6 & 5.5 & 5 & 4 & 3 \\
\hline $37^{\circ} \mathrm{C}$ & Just after acidified & - & - & - & - & - \\
& After 15 min & - & - & - & - & - \\
& After 30 min & - & - & $\sqrt{ }$ & - & - \\
& & & & & & \\
\hline$+4{ }^{\circ} \mathrm{C}$ & Just after acidified & - & - & - & - & - \\
& After 15 min & - & - & - & - & - \\
& After 30 min & - & - & $\sqrt{ }$ & - & - \\
\hline
\end{tabular}


Concentration of cystinuria solution $=100 \mathrm{mg} / \mathrm{dL}$

- Cystine crystals were not present

$\sqrt{ }$ Cystine crystals were present

\section{Effect of acetone on crystallization of cystine in-vitro}

With the addition of acetone, cystine crystallization had been occurred in the cystinuria solutions of $\geq 75 \mathrm{mg} / \mathrm{dL}$ at $\mathrm{pH} 5$ in both $37^{\circ} \mathrm{C}$ and at $+4{ }^{\circ} \mathrm{C}, 30$ minutes after the addition of acetic acid. Number of cystine crystals per HPF was highest in the solution where the ratio of cystinuria:acetone was 8:1. There was lesser number of cystine crystals where cystinuria: acetone was 2:1 and 4:1 with the deposition of amorphous phosphate over the cystine crystals. But there was no crystal formation in the solution where cystinuria:acetone was 1:1.

\section{DISCUSSION}

Cystinuria is a metabolic disorder which is an autosomal-recessive defect in reabsorption, transport of cystine and the dibasic amino acids, ornithine and arginine, plays a vital role in forming urinary stones in adult and children [Jessen \& Knoll, 2012; Fjellstedt et al., 2003], but unfortunately can be identified only in few (19-26\%) homozygous individuals. The risk has been reported due to recurrent formation of stones from cystine in the kidney, ureter and bladder though the condition is rare. The formation of cystine stone is initiated from neonatal stage and children are more vulnerable group to have cystine stones [Perera, 2016]. However, increased solubility of cystine has been reported from urine of cystine stone formers than normal subject. Cystine crystals may absent in urine deposit even in stone formers owing to miss diagnosis of cystinuria.

According to the literature there are different methods in detecting heterozygous cystinuria such as cyanidenitroprusside test, thin-layer amino acid chromatography, colorimetric estimations of cystine and ion-exchange amino acid chromatography. According to the results the highest sensitivity is given by thinlayer chromatography. The same study highlighted that the frequency of heterozygotes calculated in other studies, may be under-estimated which based on screening by the cyanide nitroprusside test. As a screening test the colorimetric estimations provides low sensitivity [Giuglian, 1987].

As the colour development of nitroprusside test from cystine is sometimes negative for stone formers, it has been suggested that nitroprusside procedure is not suitable for the screening and quantitative measurement of cystinuria [Wu, 1992]. So, it justified the need to develop a microscopic screening method for cystine. In the present study, the urine sample was collected from a healthy female of 6 years old in order to prepare cystinuria solutions. According to the physical, biochemical and microscopic examination this urine sample was identified as a normal urine sample. The urine sample was collected from a single person in order to minimize the other variables that could affect the study. Diminishing volume of acetone was added to lower the ionic strength of surrounding 
by increasing the electro static forces, after previously just acidifying with acetic acid in order to lower the $\mathrm{pH}$ up to optimum $\mathrm{PH}=5$. As acetone gives a precipitate, consisting of cystine crystals mixed with phosphates and oxalates it disturbed the clear visualization of hexagonal crystals due to deposition of phosphate over cystine which should be diminished by prior precipitation of phosphates with ammonia solution followed by calcium chloride solution before adding acetic acid.

\section{CONCLUSION}

The optimum conditions for cystine crystallization is; $\mathrm{pH} 5$ at $37^{\circ} \mathrm{C}$ and $+4^{\circ} \mathrm{C}$, 30 minutes after acidifying with acetic acid at the minimum concentration of 100 $\mathrm{mg} / \mathrm{dL}$ cystinuria and cystinuria:acetone 8:1 with minimum concentration of 75 $\mathrm{mg} / \mathrm{dL}$.

\section{ACKNOWLEDGEMENT}

We owe a special thanks to Dr. T.S.J. De Silva for the cooperation given to us during sample analyzing.

\section{REFERENCES}

Biyani, C.S. and Cartledge, J.J. ( 2006). Cystinuria-diagnosis and management. EAU-EBU update series, 4(5), pp.175-183.

Fjellstedt, E., Harnevik, L., Jeppsson, J.O., Tiselius, H.G., Söderkvist, P. and Denneberg, T.( 2003). Urinary excretion of total cystine and the dibasic amino acids arginine, lysine and ornithine in relation to genetic findings in patients with cystinuria treated with sulfhydryl

compounds. Urological research, 31(6), pp.417-425.

Giugliani, R., Ferrari, I. and Greene, L.J., (1987). An evaluation of four methods for the detection of heterozygous cystinuria. Clinicachimicaacta, 164(2), pp.227-233.

Jessen, J.P. and Knoll, T.(2012).

Management of Cystinuria. In Urolithiasis (pp. 757-765).Springer, London.

Keshavarzi, B., YavarAshayeri, N., Moore, F., Irani, D., Asadi, S., Zarasvandi, A. and Salari, M.(2016). Mineralogical composition of urinary stones and their frequency in patients: relationship to gender and age. Minerals, 6(4), p.131.

Nakagawa, Y., Asplin, J.R., Goldfarb, D.S., Parks, J.H. and Coe, F.L.( 2000). Clinical use of cystinesupersaturation measurements. The Journal of urology, 164(5), pp.1481-1485.

Perera, I.( 2016). Renal stones in children: evaluation and medical management. Sri Lanka Journal of Child Health, 45(1).

Sakandé, J., Djiguemde, R., Nikiéma, A., Kabré, E. and Sawadogo, M. (2012). Survey of urinary crystals identified in residents of Ouagadougou, Burkina Faso: Implications for the diagnosis and management of renal dysfunctions. Biokemistri, 24(3), pp.123128. 
Takasaki, E., Suzuki, T., Honda, M., Imai, T., Maeda, S. and Hosoya, Y.( 1995).

Chemical compositions of 300 lower urinary tract calculi and associated disorders in the urinary tract. Urologiainternationalis, 54(2), pp.89-94.

Tasian, G.E. and Copelovitch, L.( 2014). Evaluation and medical management of kidney stones in children. The Journal of urology, 192(5), pp.1329-1336.

Wu, J.T., Wilson, L.W. and Christensen, S. (1992). Conversion of a qualitative screening test to a quantitative measurement of urinary cystine and homocystine. Annals of Clinical \& Laboratory Science, 22(1), pp.18-29. 